\title{
A interligação entre o intersubjetivo e o intrapsíquico: (im)possibilidades na travessia da adolescência
}

\author{
La interconexión entre lo intersubjetivo y lo intrapsíquico: \\ (im)posibilidades en la travesía de la adolescencia \\ The Interconnection Between Inter-Subjective and Intrapsychic: \\ (Im)possibilities in the fidolescence Passage
}

\author{
Amanda Pacheco Machado*, Mônica Medeiros Kother Macedo* \\ "Pontifícia Universidade Católica do Rio Grande do Sul (PUCRS), Porto Alegre, Brasil.
}

Doi: http://dx.doi.org/10.12804/apl34.3.2016.05

\section{Resumo}

O presente artigo pretende problematizar os efeitos do somatório entre as intensidades intersubjetivas e intrapsíquicas que podem causar danos à importante e necessária experiência de transição da infância para a etapa adulta. A partir de uma revisão narrativa da literatura, buscou-se material nos aportes psicanalíticos e sociológicos sobre cultura, sociedade e adolescência. Pode-se considerar que o adolescer constitui-se como uma importante passagem da condição infantil para a condição adulta que pode desencadear sofrimento e angústia ao adolescente. Frente às características da atualidade, destaca-se a relevância de se considerar os efeitos do campo intersubjetivo na vivência desta passagem. Os achados permitem indicar os efeitos danosos da interligação entre as intensidades intersubjetivas e condições intrapsíquicas quando nelas predomina a impossibilidade de metabolizar as intensidades das experiências do adolescer. Diante dessa precariedade de recursos psíquicos, o adolescente pode recorrer a modalidades de resposta como a passagem ao ato, denunciando a fratura na passagem de uma condição infantil para uma condição adulta.

Palavras-chave: adolescente; cultura; psicanálise.

\section{fibstract}

This article intends to discuss the effects of the sum of their interpersonal and intrapsychic intensities that can cause damage during the important and necessary transition from childhood to adulthood. From a narrative review of the literature, we sought material in psychoanalytic and sociological contributions on culture, society and adolescence. It is considered that adolescence is an important passage from childhood to adulthood and one

* Amanda Pacheco Machado, Mônica Medeiros Kother Macedo, Grupo de Pesquisa Fundamentos e Intervenções em Psicanálise no Programa de Pós-Graduação em Psicologia (FAPSI/PUCRS), Faculdade de Psicologia (FAPSI), Pontifícia Universidade Católica do Rio Grande do Sul (PUCRS), Porto Alegre, Brasil.

Este estudo foi desenvolvido a partir de uma dissertação de mestrado, a qual contou com uma bolsa de fomento da CAPES. Correspondência a respeito deste artigo deve ser endereçada para Amanda Pacheco Machado, Rua Angelo Barbosa, 811, Cavalhada, CEP: 91740-310, Porto Alegre - RS, Brasil. Correio eletrônico: amandapm.psico@gmail.com

Cómo citar este artículo: Machado, A. P. \& Macedo, M. M. K. (2016). A interligação entre o intersubjetivo e o intrapsíquico: (im)possibilidades na travessia da adolescência. Avances en Psicología Latinoamericana, 34(3), 505-515. doi: http://dx.doi.org/10.12804/apl34.3.2016.05 
that can trigger grief and anguish in adolescents. Faced with the conditions in contemporaneity, the review points to the importance of considering the effects of inter-subjective-field experience in this passage. The findings indicate the potentially, harmful effects of interconnection between the intersubjective and intrapsychic conditions and the inability to control the rigours of the adolescent experience. Given this precarious psychological state, the teenager must use psychic work in the transition from childhood to adulthood.

Keywords: adolescent; culture; psychoanalysis.

\section{Resumen}

El presente artículo pretende problematizar los efectos de la sumatoria entre las intensidades intersubjetivas e intrapsíquicas que pueden causar daños a la importante y necesaria experiencia de transición de la infancia a la etapa adulta. A partir de una revisión narrativa de la literatura, se buscó material en los aportes psicoanalíticos y sociológicos sobre cultura, sociedad y adolescencia. Se puede considerar que entrar en la adolescencia se constituye como un importante paso de la condición infantil a la condición adulta que puede desencadenar sufrimiento y angustia al adolescente. Frente a las características de actualidad, se destaca la relevancia de considerar los efectos del campo intersubjetivo en la vivencia de este paso. Los hallazgos permiten indicar los efectos dañinos de la interconexión entre las intensidades intersubjetivas y las condiciones intrapsíquicas cuando en ellas predomina la imposibilidad de metabolizar las intensidades de las experiencias de entrar en la adolescencia. Ante esa precariedad de recursos psíquicos, el adolescente puede recurrir a modalidades de respuesta, como el paso al acto, revelando la ruptura entre el paso de una condición infantil a una condición adulta.

Palabras clave: adolescente; cultura; psicoanálisis.

A definição conceitual da adolescência e sua compreensão só foram possíveis, de acordo com Kehl (2007), a partir da Modernidade. Uma das principais razões para tal, segundo Ariés (1981), refere-se à confusão e a indiferenciação entre a infância e a adolescência que perdurou até o Século XVIII. Se durante muito tempo desconsiderou-se as especificidades da condição de ser adolescente, no contexto contemporâneo, pelo contrário, observa-se um crescente interesse de diversas áreas do saber na população juvenil. Nesse sentido, no que tange a ótica da Psicanálise sobre o adolescer, destacam-se as singulares intensificações que a cultura do excesso vem imprimindo, bem como as singulares intensidades intrapsíquicas próprias a vivência desta passagem (Mendes \& Paravidini, 2007; Monteiro, 2011).

Segundo Nogueira Filho (1999), a adolescência não pode ser tomada de uma forma indeterminada ou como um conceito universal. A única faceta deste período que se estende a todos os adolescentes envolve a representação de uma passagem de um status infantil para um status adulto. Assim, conforme Macedo, Dockhorn e Iensen (2010), compreende-se que a experiência do adolescente é singular e complexa, não sendo passível de normatizações. Trata-se de um processo marcado por complexas transformações físicas e psíquicas, cuja compreensão dos fatores envolvidos não deve se dar de forma causal ou linear.

$\mathrm{Na}$ adolescência predominam "as dúvidas, os interrogantes, os medos, as incertezas, os sofrimentos, mas, sobretudo, a capacidade de transformação" (Rother Hornstein, 2006, p. 118). O sujeito adolescente percebe-se, de acordo com a autora, diante de uma encruzilhada de fragilidades e de potencialidades que lhe impõem incessantes interrogações sobre a identidade e o devir. Desta forma, o adolescer, em virtude da reaparição dos conflitos infantis, põe em xeque a organização psíquica do sujeito. Esta complexa passagem na qual, estarão entrelaçados e exigidos processos relativos ao corpo, ao psíquico e ao social, será palco de importantes ressignificações: da história; das constituições sexuais, narcísicas, pulsionais; das relações; das identificações; e da subjetividade. Para Rother Hornstein (2006), o corporal terá 
destaque na adolescência devido à irrupção da puberdade, a qual exige a instauração de um trabalho de simbolização que permita ao sujeito novas modalidades de relacionar-se com os outros, com o meio que o circunda e com o que lhe é proposto pelo imaginário social.

Nessa direção, a adolescência também inclui a referência um processo histórico singular que remete as demandas da cultura na qual ocorre. Para Sternbach (2006), a cultura é responsável por produzir organizações subjetivas concordantes com "suas propostas identificatórias, seus ideais, suas proibições e suas impossibilidades identificatórias" (p. 51). A partir dessa perspectiva, o adolescente, segundo a autora, ainda que não se dê conta, personifica o discurso propagado culturalmente a respeito de quem deve ser e o que deve fazer em consonância com sua faixa etária.

As particularidades observadas em relação à adolescência, relativas ao campo intersubjetivo, são tomadas como um primeiro eixo de problematização nesta análise crítica. Entende-se que a consideração às demandas culturais constitui-se uma importante via de reflexão a respeito das manifestações adolescentes que têm sido observadas na atualidade. Como segundo eixo de problematização recorre-se, portanto, a uma leitura que aborda o adolescer desde a perspectiva de condições intrapsíquicas. Não se pretende apresentar uma análise independente destes dois eixos, mas, ao contrário, trata-se de explicitar, posteriormente, a interligação destes eixos para problematizar as dramáticas consequências da precariedade de recursos intrapsíquicos necessários para o enfrentamento de demandas culturais predominantes na contemporaneidade.

A passagem para adolescência engendra uma intensa e violenta reviravolta no equilíbrio psíquico, nas organizações pulsionais e narcísicas (Padrão, Mayerhoffer, Silva, \& Cardoso, 2006). Trata-se de um momento marcado por fragilidades decorrentes do impacto das mudanças e das novas exigências às bases narcísicas do sujeito. Nesse sentido, de acordo com as autoras, o adolescer "normal" apresenta, por si só, matizes traumáticas e violentas. A impotência frente às mudanças que fogem ao controle, acrescida da fragilidade das fronteiras narcísicas delega a adolescência experiências subjetivas complexas, que desencadeiam angústia e sofrimento psíquico. Destaca-se, assim, a revivência do desamparo, componente constitutivo da identidade humana. Segundo Palmeira, Mayerhoffer, Mariz e Cardoso (2006), em virtude das condições próprias do adolescer, pode-se considerar que nesta etapa dá-se um incremento ao desamparo, que pode intensificar as conflitivas adolescentes.

Nesta direção, destaca-se o impacto que o "encontro" entre as demandas culturais e as condições intrapsíquicas do adolescente pode assumir. As características da contemporaneidade podem também, conferir um incremento à inerente condição humana de desamparo, provocando manifestações, com frequência, de exposição à riscos como uma única via utilizada pelo adolescente como descarga de um mal-estar interno (Palmeira et al., 2006). Diante deste panorama, é possível considerar que a fronteira, na adolescência, entre o traumático "normal", que alcança via de elaboração dos conflitos, e o traumático "patológico", que transcende os limites da representação, torna-se frágil. No âmbito clínico, de acordo com Padrão et al. (2006), observa-se a alta incidência de adolescentes que tem suas experiências intensamente atravessadas pela violência. Como exemplo, as autoras citam situações que vão desde profunda melancolia e depressão "até outros estados-limites, tais como as patologias adictivas - a drogadicção, as anorexias e bulimias - assim como patologias de auto e hetero-agressividade" (p. 140).

Compreende-se, a partir destes assinalamentos que, na interligação do campo intersubjetivo com o contexto intrapsíquico na adolescência, comportamentos de experimentação e teste de limites, esperados nesta etapa, podem adquirir caráter preocupante ao se apresentarem perpassados por uma condição de excesso. É possível considerar, 
desde as manifestações que incidem na clínica adolescente atual, que as experimentações, nesta configuração, não ofertam ao sujeito modalidades de enfrentamento de seus conflitos. Dessa maneira, faz-se mister construir vias de problematização sobre os efeitos do somatório entre excessos decorrentes de intensidades intersubjetivas e intrapsíquicas que podem, ao extrapolarem o "esperado" para esta etapa de travessia entre a infância e a adultez, causar danos à necessária experiência de elaboração de lutos e consolidação das aquisições psíquicas. Com este intuito, a partir de uma análise crítica, recorre-se a apresentação de momentos históricos da construção do conceito da adolescência sob o olhar da Psicanálise.

\section{Conceitualização da adolescência e as demandas do cenário intersubjetivo}

Na Idade Média, segundo Ariès (1981), não havia espaço para a noção de adolescência, em decorrência da confusão que existiu até o século XVIII entre as noções de infância e adolescência. O principal motivo para isso era, segundo o autor, a indiferenciação dos fenômenos humanos sob uma ótica biológica. A infância não era limitada pela puberdade, mas, sim, pelo critério relacionado à questão da dependência em relação a outras pessoas. Assim, só era possível ultrapassar essa fase, quando se abandonava a condição de dependência. Os sujeitos que não eram mais considerados dependentes, portanto, passavam a pertencer ao que se denominava juventude, noção relacionada predominantemente à força e à capacidade física (Ariés, 1981).

Entre os Séculos XIX e início do Século XX, de acordo com Grossman (1998) e Passerini (1996), estabeleceu-se o conceito de adolescência como uma etapa distinta do ciclo vital. Passerini (1996) afirma que a virada de Século, ao promover mudanças na estrutura familiar vigente e nas relações entre seus membros, possibilitou ferramentas para a invenção da adolescência. Nessa direção, Ariés
(1981) aponta que o primeiro adolescente moderno típico foi Siegfried da música de Wagner, a qual expressava a mistura de inocência, de força física, de espontaneidade e de alegria de viver.

As duas Grandes Guerras, também, desempenharam papel fundamental nesse processo de caracterização da adolescência, principalmente em decorrência da violência e da banalização da vida (Outeiral, 2001). Com o término da Primeira Guerra Mundial, em 1918, observou-se, de acordo com Gutierra (2003), um movimento por parte dos jovens que haviam lutado em posições de frente na batalha, de oposição aos combatentes mais velhos. Tal processo resultou na conquista de um espaço próprio à adolescência, fazendo com que, neste período da vida fosse considerado que a infância foi deixada para trás e a maturidade projetada à frente.

No período entre guerras, de acordo com Ariés (1981), a juventude tornou-se temática constante na literatura, preocupando os moralistas e os políticos, que passaram a desejar saber o que pensavam os jovens. Assim, a noção de juventude surgiu associada à possibilidade de aportar valores novos e de trazer vida para uma sociedade velha (Ariés, 1981). Essa noção elevou o adolescente ao posto de herói do Século XX, considerado o Século da adolescência (Ariés, 1981; Justo, 2005). Nesse sentido, constata-se a passagem de uma época na qual não havia reconhecimento da especificidade do adolescente para outro tempo no qual a adolescência é considerada a idade favorita, despertando nas pessoas o desejo de alcançá-la e de nela permanecer por muito tempo.

Seguindo essa linha de pensamento, no decorrer do Século XX, Justo (2005) assinala ser possível observar um movimento de elevação da adolescência a uma representação máxima do que se refere ao jovem, à potência, à beleza, ao espírito livre, ao gozo, à disposição para mudanças, entre outras características. Essa caracterização fez com que esse período do ciclo vital passasse a ser cobiçado e prestigiado. A adolescência passou a ocupar, portanto, um lugar de ideal cultural no 
contexto social (Kehl, 2007; Rocha \& Garcia, 2008; Savietto, 2010).

Este processo de elevação social da noção de adolescência consolidou-se na década de 1960. Nesta época, segundo Le Breton (2014), em diversos países, instalou-se uma rebelião da juventude. A principal reivindicação dos jovens era decorrente da insatisfação com as condições de vida, marcadas pela repressão da cultura vigente. Nesse sentido, o autor considera que no âmago deste movimento estava a oposição dos jovens aos padrões culturais seguidos por seus pais, acrescida da recusa de um vir a ser como as figuras parentais. A partir da luta da juventude, a moral impositiva e repressora, aos poucos, cedeu lugar às possibilidades de desenvolvimento individual. A busca de independência da juventude, conforme assinala Le Breton (2014), almejava destituir as modalidades de autoridade vigentes no seio familiar, da escola e da universidade. Dessa maneira, ao conquistar a emancipação em relação à tutela dos adultos, o jovem passa a opor-se a condição de submissão.

O referido movimento social, segundo Le Breton (2014), desencadeou um processo de inversão de valores que atingiu tanto aos adolescentes como aos adultos. Se, antes, era possível observar um movimento por parte dos adolescentes, de buscar a imitação dos adultos, a partir de 1960 passou-se a observar os adultos querendo ser reconhecidos como adolescentes, chegando, algumas vezes, a imitá-los (Kehl, 2007). Nessa direção, segundo a autora, pais e filhos passam a viver a partir dos mesmos valores, elevando à dimensão de culto os mesmos símbolos sociais. Dessa maneira, descortina-se o impeditivo de que haja uma disputa real e saudável entre gerações.

Ainda na década de 60, Birman (2006) assinala o surgimento de outro movimento social de grande relevância e influência na maneira como a infância e a adolescência ocorrem e são vistas atualmente. Esse período foi palco, também, da revolução feminista, a qual reivindicava a autonomia das mulheres e direitos iguais aos dos homens em todos os espaços sociais. O movimento feminino teve impacto em diversos cenários, em especial na família. Vislumbra-se, segundo o autor, efeitos nos quais tanto o pai, como a mãe passaram a ter seus próprios projetos de vida, independentes da esfera familiar. Assim, desencadeou-se uma grande mudança na relação entre pais e filhos. Com ambas as figuras parentais tendo seus próprios projetos, tornou-se necessário que o pai estivesse mais presente no cuidado dos filhos do que costumava estar, como forma de equilibrar as mudanças (Birman, 2006). Porém, não foi o que ocorreu. Esse desequilíbrio contribuiu para que, nos sujeitos, frutos dessa nova configuração familiar se apresentassem uma série de consequências na constituição psíquica. Como impacto maior, surgiu o sentimento de abandono em função da falta de equilíbrio entre as ausências parentais (Birman, 2006). É importante ressaltar, conforme indica o autor, que as mudanças ocorridas nos cuidados dos pais com os filhos não ocorreram devido ao afastamento da mulher do âmbito familiar e do lar; a principal causa dessas mudanças relaciona-se à impossibilidade de as figuras parentais equilibrarem seus projetos externos com a esfera familiar.

O resgate histórico da construção do conceito da adolescência possibilita que sejam identificados, no cenário cultural e social, dois momentos cruciais: um momento em que a adolescência assume seu lugar especifico dentre as etapas do ciclo vital e outro no qual o adolescente passa a ser considerado como integrante do sistema social. Percebe-se que, diante da definição mais clara dessa etapa, seus aspectos singulares passam a ser considerados e, também percebe-se mais claramente, a intensidade das manifestações nela presentes. Tais elementos oferecem ferramentas para a reflexão e a compreensão dos fenômenos sociais implicados no modo como a adolescência vem se estruturando no contexto social atual.

A adolescência, segundo Le Breton (2014) desde aportes da Sociologia, constitui-se como um período de abertura ao outro, principalmente 
em virtude da passagem da sexualidade infantil para a sexualidade genital relativa à maturação. A infância é deixada para trás, ao mesmo tempo em que, o sujeito realiza uma reconstrução do si mesmo e de seus investimentos. Nesse sentido, conforme aponta o autor, nesta passagem, o sujeito é confrontado com o sentimento de identidade, suscetível a diversas modulações de acordo com as circunstâncias e o olhar dos outros, mas organizado a partir de uma continuidade. As fronteiras do si mesmo reconstroem-se a partir da sensibilidade do adolescente aos encontros, aos acontecimentos e aos comentários ouvidos sobre si. O sentimento de identidade, segundo o autor, caracteriza-se pela sensibilidade às experiências internas e externas que incessantemente exigem do sujeito à busca de bases narcísicas sólidas. Trata-se, portanto, de um processo de "subjetivação, de uma apropriação simbólica de si” (Le Breton, 2014, p. 67).

Nesta direção, Minerbo (2013) ressalta que, no contexto atual, houve um processo de fluidez das instituições, o que acabou por torná-las mais frágeis. Este enfraquecimento produz, de acordo com a autora, uma perda simbólica em relação à construção da identidade dos sujeitos. Assim, este processo tem que ocorrer a partir do si mesmo, sem contar com o amparo de algum referencial sólido. Ao considerar a importância dos modelos e significados ofertados pelas instituições para a constituição do psiquismo, Minerbo (2013) constata a árdua tarefa que deverá ser realizada pelo sujeito, a fim de conferir sentido à realidade e simbolizar suas experiências. Sem significados e sem modelos identificatórios sólidos, tudo passa a ser possível. Nesse sentido, de acordo com a autora aqueles sujeitos que não conseguem encontrar um caminho para realizar tal tarefa, acabam por sentirem-se perdidos, impossibilitados de estabelecer e almejar um projeto de vida.

Dedicando-se ao estudo do entrelaçamento entre a adolescência e a atualidade, Kehl (2007) propõe que o cenário ocidental vem passando por um processo de teenagização. Trata-se, conforme a autora, de uma sociedade que erigiu a adolescência como ideal cultural para todas as idades. Nesse processo, o lugar do adulto fica permanentemente vazio, pois ninguém está disposto a ocupá-lo e assumir a função de representante da lei frente às gerações que o sucedem. Na publicidade, assinala Kehl (2007), o apelo para o "sem limites" da vida adolescente é disseminado de forma indiscriminada. A adolescência torna-se, assim, representante atual das formas imaginárias do mais-gozar, explicitando o pedido para que o sujeito ultrapasse os limites do prazer, oferecendo risco ao corpo e ao psíquico. Frente à tamanha idealização da adolescência, os pais, indica Kehl (2007), sentem-se desautorizados a impor impedimentos aos excessos dos filhos. Os adolescentes, por sua vez, parecem viver em um mundo no qual as normas são estabelecidas por eles e para eles.

As contribuições de Minerbo (2013) e Kehl (2007) permitem contemplar os excessos que desde a cultura podem somar-se as demandas próprias ao adolescer. Neste sentido, os aportes referidos pelas autoras permitem destacar uma perspectiva que problematiza, no campo intersubjetivo, os efeitos das demandas culturais contemporâneas. A elevação do conceito não significou necessariamente mais atenção e cuidado a fragilidades que na adolescência se apresentem. É a partir dessa linha de consideração acerca das singulares vivências de um sujeito que a adolescência vem sendo estudada no âmbito da Psicanálise.

\section{O sujeito adolescente: o necessário trabalho intrapsíquico}

Em "Três Ensaios sobre a Teoria da Sexualidade", Freud (1905 [1996]) amplia o olhar sobre a puberdade, considerando-a como um processo, que além das transformações corporais, compreende, também, uma experiência subjetiva. Nela, segundo Freud (1905 [1996]), ocorrem dois processos simultâneos: o desligamento das figuras primordiais e, com isso, a possibilidade de estabelecer novos 
investimentos amorosos e sociais. Percebe-se nestas iniciais considerações freudianas a referência a interligação do intrapsíquico com o intersubjetivo. $\mathrm{Na}$ impossibilidade de realizar e concluir estas reordenações necessárias no campo dos investimentos do sujeito, o autor indica a possibilidade de irromperem perturbações psíquicas.

O adolescer, segundo Rother Hornstein (2006), corresponde a um tempo de ruptura que solicita uma série de trabalhos simbólicos para estabelecer reorganizações que comportem uma matriz relacional e o acesso a eleições de objetos possíveis. O necessário movimento de desligar-se das figuras primordiais da vida infantil, segundo Savietto (2010), constitui-se como árduo e doloroso, mas fundamental para a consolidação da identidade do sujeito adolescente. Renunciar aos pais idealizados e objetos de desejo envolve, portanto, um significativo remanejamento do referencial identificatório. Torna-se necessário ao adolescente, conforme a autora, promover identificações secundárias que lhe possibilitem construir outros modelos, diferentes dos parentais, dando contornos a uma identidade adulta. Nesse sentido, compreende-se que a reorganização das identificações, posta em xeque na adolescência, implica necessariamente na elaboração do luto dos pais da vida infantil. Na atualidade, de acordo com Savietto (2010), é possível levantar a hipótese de que há uma forte resistência, por parte dos adolescentes, a realização do trabalho de luto dos pais infantis. Diante dessa resistência, o remanejamento das identificações é obstruído, tornando árduo o investimento em novos objetos. Assim, conforme assinala a autora, ao invés de realizar novos movimentos de investimento, predomina, por parte do adolescente, a manutenção do robusto vínculo com os pais idealizados da vida infantil. A preponderância desta resistência colabora "para a manutenção de um funcionamento mental infantil e essencialmente narcísico" (Savietto, 2010, p. 51).

Ao opor-se ao luto dos pais infantis, para Savietto (2010), o adolescente ergue barreiras ao desmanche desses laços e para a reconstituição dos processos identificatórios. O predomínio de dificuldades para realizar as necessárias rupturas repercute na travessia e na "superação" da vivência da adolescência. A impossibilidade de realizar movimentos de ruptura dos vínculos e das identificações, segundo Savietto (2010), delimita o enfraquecimento das potencialidades próprias à adolescência, e o fortalecimento de um potencial mortífero, destrutivo, no qual se situa como possível manifestação a adicção às drogas, por exemplo.

Nesta perspectiva, é fundamental elucidar, conforme Rother Hornstein (2006) que, ao mesmo tempo em que a adolescência constitui-se como momento propício para a eclosão de perturbações patológicas, estas desorganizações requerem uma compreensão diferente daquelas referentes à infância e a adultez. A especificidade da puberdade, do protagonismo pulsional e dos trabalhos próprios ao adolescer conferem uma dinâmica peculiar ao surgimento de uma psicopatologia na adolescência. Dessa maneira, segundo Macedo et al. (2010), existe uma linha tênue entre aquilo que permite diferenciar os excessos característicos dos conflitos vivenciados pelo sujeito adolescente e os excessos marcados pela vigência de experiências traumáticas. Na vigência destas experiências de excesso, a impossibilidade de metabolizar as intensidades psíquicas remetem à condição frágil e explicita o que está além do esperado no transcorrer da experiência da adolescência (Macedo et al., 2010). Cabe, neste sentido, explorar aspectos que desde o campo intersubjetivo contribuem para o acréscimo de intensidades psíquicas na vivência da adolescência.

\section{$O$ excesso no adolescer: tessituras entre $o$ intersubjetivo e o intrapsíquico}

As trajetórias de vida marcadas pela modalidade de experiências traumáticas, segundo Padrão et al. (2006), desvelam a fragilidade dos recursos psíquicos para enfrentar as demandas da vida. Macedo et al. (2010) indicam que, nestas modalidades de 
experiências, descortina-se a expressão de um esvaziamento narcísico, que se utiliza da cisão do $\mathrm{Eu}$ como maneira de defender-se daquilo que não se encontra passível de estabelecer ligação psíquica. Nesse sentido, de acordo com os autores, instala-se a impossibilidade de o sujeito estabelecer fronteiras que delimitem a noção do Eu e do nãoEu. Além disso, evidencia-se, também, de acordo com Padrão et al. (2006), um excesso traumático proveniente de um laço afetivo excessivo e violento com a alteridade interna, fruto de experiências no campo intersubjetivo. Tal encontro que não fora bem-sucedido com o outro, de acordo com as autoras, faz com que o sujeito, para se defender de intensidades psíquicas, utilize respostas precárias, como a passagem ao ato, por exemplo.

Diante do excesso que invade e se alastra, o psiquismo, segundo Birman (2012), recorre à ação na tentativa de se livrar dele para não ficar sob a ameaça de um estado de paralisação decorrente da disseminação da angústia. Na impossibilidade de descartar e descarregar o excesso pela via da ação, o aparelho psíquico convoca o corpo. Este destino no qual o excesso retorna para o si mesmo, de acordo com o autor, indica que, na atualidade, o psiquismo recorre com maior frequência a passagem ao ato e não ao acting-out. Faz-se mister, portanto, diferenciar estas modalidades de ação. Conceitualmente a principal diferença relaciona-se "à fragilidade e à ausência de processos de simbolização na passagem ao ato, enquanto estas estariam presentes no acting-out (atuação)" (Birman, 2012, p. 97). A simbolização assinala o autor, apresenta-se $n a$ ação e como ação, o que caracteriza uma realização e uma manifestação do inconsciente. Na passagem ao ato, pelo contrário, a ação é crua e marcada por uma brutalidade, destituída de qualquer resquício simbólico. O excesso, portanto, retorna sobre o si mesmo, implodindo no psiquismo e no organismo.

O predomínio desse tipo de "ação" conduz a uma questão profícua quando se considera o processo de adolescer e a cultura vigente. Diante de impasses fundamentais entre as condições frágeis do sujeito e a intensidade das demandas e exigências sociais instaura-se o incremento da condição de desamparo. O desamparo, elemento constitutivo da subjetividade humana, decorre segundo Savietto e Cardoso (2009), da noção de insuficiência que, nos primórdios vincula-se a condição psicomotora do bebê, mas, fundamentalmente, diz respeito à insuficiência do psiquismo em lidar com o excesso de excitação pulsional daquele momento. $\mathrm{Na}$ adolescência, diante do excesso o desamparo que se constata é da insuficiência de recursos que poderiam se fazer presentes. Assim, pode-se considerar que esta condição de desamparo é incrementada e se aproxima da qualidade de excesso uma vez que se soma as já e esperadas intensas exigências pulsionais e demandas de trabalho diante de transformações próprias à adolescência. Savietto e Cardoso (2009) destacam que para dar conta do excesso pulsional, o sujeito precisa metabolizá-lo a fim de representá-lo simbolicamente. Porém diante do predomínio de experiências traumáticas, a interligação entre o campo intrapsíquico e intersubjetivo mostra a dura faceta desta impossibilidade de metabolização: de um lado tem-se um sujeito impossibilitado de recorrer a recursos psíquicos para enfrentar as demandas, de outro lado, tem-se uma cultura pautada em ideias de consumo que carece de referenciais simbólicos. Descortinam-se, assim, os efeitos dramáticos que os excessos internos e externos podem imprimir no adolescer.

$\mathrm{Na}$ atualidade, de acordo com Palmeira et al. (2006), a sensação de impotência se impõe com frequência à vida do sujeito. A busca de ideais e, portanto, de novos modelos identificatórios, processo fundamental para a constituição e a consolidação da identidade do adolescente, também se torna prejudicada. Tais prejuízos ocorrem, conforme as autoras, na medida em que, na contemporaneidade, percebe-se que não é oferecido nada que o adolescente possa fazer para que lhe seja permitido atingir o ideal de completude demandado. O sujeito adolescente contemporâneo, em plena vivência da transformação de suas habituais 
formas de ser e estar no mundo, se vê confrontado com a incessante apresentação cultural de ideais a serem alcançados ao mesmo tempo em que são descontruídos e substituídos por novas e transitórias demandas. Assim, mesmo sem reconhecer nos espaços de uma identidade própria é exigido a ser "um sujeito múltiplo" (Palmeira et al., 2006) e cobrado a dar conta com sucesso de todas as demandas com as quais se vê confrontado socialmente. Essa dinâmica incessante e na qual se torna impossível ter êxito, pode conduzir o adolescente a deparar-se com um incremento à intensidade do estado de desamparo. Como reflexo dessa situação, segundo Palmeira et al. (2006), observa-se, com frequência, adolescentes em estado de desilusão e desesperança em relação a si mesmos e a seus projetos quando se deparam com tais ideais inatingíveis, aparentando estarem sempre à espera de algo ou alguém que possa lhes oferecer um sentido para a própria existência e completar qualquer sentimento de falta ou de frustração. Diante da impossibilidade de enfrentamento e elaboração dos lutos relativos ao infantil, instaura-se na adolescência o excesso de desamparo que delega ao outro, via predomínio da passividade do sujeito, a satisfação imediata e preenchimento do vazio da dor diante da vida cotidiana.

A intolerância a frustração e a falta, segundo Le Breton (2014) é outra importante marca que vem sendo observada com frequência na juventude contemporânea. Para o autor, em uma configuração familiar na qual o sujeito desconhece a proibição, o processo de inserção social irá se constituir como uma tarefa árdua. A falta de fronteiras entre o Eu e o outro conduz a uma confusão entre o dentro e o fora, provocando no adolescente um estado de indiferenciação e confusão. De acordo com o autor, são adolescentes que sofrem, que buscam limites, mas que principalmente, estão em busca daquilo que são. Nesta modalidade de experiência, a fragilidade da identidade intensifica-se, tornando qualquer frustração e qualquer espera insustentável. Dessa maneira, conforme assinala Le Breton (2014), ao nunca ter se deparado com um não organizador, o sujeito fica destituído do registro de interdição, mantendo um funcionamento psíquico arcaico e onipotente.

Nessa perspectiva, Monteiro (2011) aponta que a falta de interdições ao comportamento do sujeito adolescente desvela efeitos tanto no que se refere a promover seus recursos psíquicos, como o que alude a posicionar-se de forma distinta e autônoma diante das intensas demandas sociais. Observa-se, de acordo com Mayer (2001), uma atitude parental condescendente, incapaz de colocar limites ao sujeito, em decorrência de, muitas vezes, encontrar-se, também, em uma condição de desamparo apoiada por uma sociedade que não consegue impor medidas repressivas. Ao se perceberem diante de tantos excessos, conforme indica o autor, os adolescentes acabam demonstrando falhas no processo de simbolização e de elaboração psíquicas, as quais poderiam dar conta de tais demandas e passam a expor-se, na maioria das vezes, a situações de risco, em que se utilizam da passagem ao ato como forma de descarga dessas intensidades.

Para Mayer (2001), na mesma direção assinalada por Birman (2012), o ato é uma demonstração da falta de esperança, como se o sujeito se rendesse aos excessos pelos quais é invadido, sem possibilidade de pensar sobre eles. $\mathrm{O}$ ato surge, dessa maneira, de acordo com Macedo, Azevedo e Cas$\tan$ (2010), como uma tentativa de aliviar a dor do desamparo e lidar com aquilo que não é passível de elaboração. Assim, propõe-se compreender, nesta análise crítica, o predomínio da passagem ao ato na adolescência como o maior e mais contundente testemunho do fracasso da interligação entre as exigências que se dão no campo intrapsíquico e o necessário respaldo que o adolescente precisa encontrar no contexto intersubjetivo. Nesta perspectiva, a passagem ao ato no adolescer denuncia uma dramática fratura na passagem de uma condição infantil para uma condição adulta. 


\section{Considerações finais}

A adolescência constitui-se como uma importante experiência de travessia de uma condição infantil para uma condição adulta. Trata-se de um momento de fragilidade narcísica marcado pelas necessárias transformações e recomposições psíquicas que podem ou não se constituírem em fatores desencadeantes de angústia e de sofrimento para o sujeito. Desta forma, a adolescência pode comportar um fator de transformação e desafios pertinentes as suas conflitivas, ou pode contemplar experiências cujas intensidades extrapolam a capacidade de metabolização psíquica. Nesta perspectiva, que desvela diferentes possibilidades de enfrentamento com as demanda do adolescer, constata-se que no cenário contemporâneo, com certa frequência, pode ocorrer a intensificação dos comportamentos de experimentação e de teste de limites, típicos deste momento da vida. Assim, o adolescer pode passar a contemplar situações de risco a saúde psíquica.

Desde a ótica da Psicanálise, é possível considerar que, em virtude das especificidades do processo de adolescer, as fronteiras que delimitam o esperado e aquilo que transcende a esta experiência, podem manifestar-se de forma tênue. No intuito de construir uma análise crítica sobre a temática da adolescência e seu necessário enfrentamento com conflitivas psíquicas, físicas e culturais, foram propostos neste texto dois eixos de problematização. O primeiro eixo é relativo às particularidades observadas, mais especificamente, no campo intersubjetivo; já o segundo eixo proposto refere-se a compreensão do adolescer considerando-se as condições intrapsíquicas. Dessa maneira, a partir da interligação dos dois eixos temáticos foram abordadas as danosas consequências no processo de adolescer quando o cenário fica invadido por excessivas intensidades. Assim, o excesso ocorrido na sobreposição de demandas intrapsíquicas e intersubjetivas, instala o incremento do desamparo e, obtura o necessário trabalho psíquico de elaboração dos conflitos, fraturando a passagem da condição infantil para a condição adulta.

Diante das características da sociedade contemporânea, pautada na imediatez e no imperativo do consumo, cabe interrogar a respeito das condições ofertadas no campo intersubjetivo as transformações e conflitivas experenciadas na adolescência. $\mathrm{O}$ adolescer exige tempo para elaboração das vivências infantis e tempo para poder alcançar a condição adulta. A cultura exige respostas rápidas a incessantes demandas, não outorgando, muitas vezes, ao adolescente o tempo necessário para metabolizar a intensidade de suas experiências. Nesta direção, o predomínio do "recurso" a passagem ao ato explicita, no adolescer, o fracasso da construção de alternativas simbólicas, da elaboração de lutos e da necessária ressignificação no campo identitário.

Tomando a noção de travessia para descrever o processo da adolescência, conclui-se que diante de condições externas tempestuosas e desfavoráveis à navegação, o iniciante timoneiro pode perder $\mathrm{o}$ rumo. Os indicativos externos que poderiam auxiliá-lo como pontos de referência quando ausentes ou precários dificultam em muito a travessia.

\section{Referências}

Ariés, P. (1981). História social da criança e da família. Rio de Janeiro: LTC.

Birman, J. (2006). Tatuando o desamparo. In M. R. Cardoso (Org.), Adolescentes (pp. 25-43). São Paulo: Escuta.

Birman, J. (2012). O sujeito na contemporaneidade: espaço, dor e desalento na atualidade. Rio de Janeiro: Civilização brasileira.

Freud, S. (1905 [1989]). Três ensaios sobre a teoria da sexualidade. In J. Strachey (Ed. e Trad.), Edição standard brasileira das obras psicológicas completas de Sigmund Freud (Vol. 7, pp. 119-229). Rio de Janeiro: Imago.

Grossman, E. (1998). A adolescência através dos tempos. Adolescência Latinoamericana, 1(2), 68-74. 
Gutierra, B. C. C. (2003). Adolescência, psicanálise e educação-o mestre possível de adolescentes. São Paulo: Avercamp.

Justo, J. S. (2005). O "ficar" na adolescência e paradigmas de relacionamento amoroso da contemporaneidade. Revista do departamento de Psicologia-UFF, 17(1), 61-77.

Kehl, M. R. (2007). A juventude como sintoma da cultura. In R. Novaes \& P. Vannuchi (Orgs.), Juventude e sociedade: trabalho, educação, cultura e participação (pp. 89-114). São Paulo: Editora Fundação Perseu Abramo.

Le Breton, D. (2014). Una breve historia de la adolescência. Ciudad autónoma de Buenos Aires: Nueva visión.

Macedo, M. M. K., Azevedo, B. H., \& Castan, J. U. (2010). Adolescência e psicanálise. In M. M. K. Macedo (Org.), Adolescência e Psicanálise: Intersecções possíveis (pp. 15-54). Porto Alegre: EDIPUCRS.

Macedo, M. M. K., Dockhorn, C. N. B. F., \& Iensen, S. A. L. (2010). A questão do padecimento na clínica psicanalítica com adolescentes. In M. M. K. Macedo (Org.), Adolescência e Psicanálise: Intersecções Possiveis (pp. 91-109). Porto Alegre: EDIPUCRS.

Mayer, H. (2001). Passagem ao ato, clínica psicanalítica e contemporaneidade. In M. R. Cardoso (Org.), Adolescência: reflexões psicanaliticas (pp. 81-101). Rio de Janeiro: NAU editora.

Mendes, E. D. \& Paravidini, J. L. L. (2007). Os significantes da escuta psicanalítica na clínica contemporânea. Psychê, 11(20), 99-116.

Minerbo, M. (2013). Ser e sofrer hoje. Ide, 55, 31-42.

Monteiro, R. A. (2011). Desamparo e intensidades em ato na adolescência: riscos ao devir (Dissertação de Mestrado, Pontifícia Universidade Católica do Rio Grande do Sul, Porto Alegre).

Nogueira Filho, D. M. (1999). Toxicomania. São Paulo: Escuta.
Outeiral, J. (2001). Adolescência: modernidade e pós-modernidade. In C. Weinberg (Org.), Geração delivery: adolescer no mundo atual (pp. 13-28). São Paulo: Sá.

Padrão, C. B., Mayerhoffer, E. L., Silva, P. C. M., \& Cardoso, M. R. (2006). Trauma e violência pulsional: a adolescência como situação limite. In M. R. Cardoso (Org.), Adolescentes (pp. 135145). São Paulo: Editora Escuta.

Palmeira, C. G., Mayerhoffer, E. L., Mariz, N. N., \& Cardoso, M. R. (2006). Desamparo e melancolia na adolescência contemporânea. In M. R. Cardoso. (Org.), Adolescentes (pp. 157-168). São Paulo: Editora Escuta, 2006.

Passerini, L. (1996). A juventude, metáfora da mudança social. Dois debates sobre os jovens: A Itália fascista e os Estados Unidos da década de 1950. In G. Levi \& C. Schimitt (Orgs.), História dos jovens 2: a época contemporânea (pp. 319382). São Paulo: companhia das Letras.

Rocha, A. P. R. \& Garcia, C. A. (2008). A adolescência como ideal cultural contemporâneo. Psicologia: Ciência e Profissão, 28(3), 622-631.

Rother Hornstein, M. C. (2006). Entre desencantos, apremios e ilusiones: barajar y dar de nuevo. In M. C. Rother Hornstein (Org.), Adolescencias: trayectorias turbulentas (pp. 117-136). Buenos Aires: Paidós.

Savietto, B. B. A. (2010). Drogadicção na juventude contemporânea: a "intoxicação" pelo outro (Tese de Doutorado, Universidade Federal do Rio de Janeiro, Rio de Janeiro).

Savietto, B. B. A. \& Cardoso, M. R. (2009). A drogadição na adolescência contemporânea. Psicologia em Estudo, 14(1), 11-19.

Sternbach, S. (2006). Adolescencias, tiempo y cuerpo en la cultura actual. In M. C. Rother Hornstein (Org.), Adolescencias: trayectorias turbulentas (pp. 51-80). Buenos Aires: Paidós.

\section{Recebido: maio 4, 2015 Aprovado: outubro 29, 2015}


